\title{
Emerson and I Stare at the Sunset
}

Saffron flaring from below beyond the land, never ends, exactly, but where the mind wants a boundary gives over, infinite, to a blue unison of ice and fire.

One star is quickening and a new moon cool as flutesong.

The only earth-caught thing:

a whittling of fir trees

lit black.

I am nothing. I see all, says the transcendentalist his wide-eyed way of bracketing the world. And I with my doubts squint at the clarifying dusk, the heaven becoming nothing like itself, evening. Evening. Evening till I cannot disbelieve my eyes. 